\section{An improved scavenger box for the cryoprobe}

\section{To the Editor:}

Some cryosurgical systems use nitrous oxide, and it has been pointed out that cryoprobe leakage produces excessive nitrous oxide concentrations in the $\mathrm{OR},{ }^{1-3}$ with $\mathrm{N}_{2} \mathrm{O}$ levels as high as 900 ppm. $^{3}$ Scavenger devices have been recommended, ${ }^{1.2}$ and one scavenger box reported reduces the $\mathrm{N}_{2} \mathrm{O}$ concentrations by more than 50 per cent. ${ }^{3}$ However, even with the scavenger box, $\mathrm{N}_{2} \mathrm{O}$ concentrations near the anaesthetist were in the range of 150 to $300 \mathrm{ppm},{ }^{3}$ considerably higher than NIOSH recommendation of $25 \mathrm{ppm}^{4}$

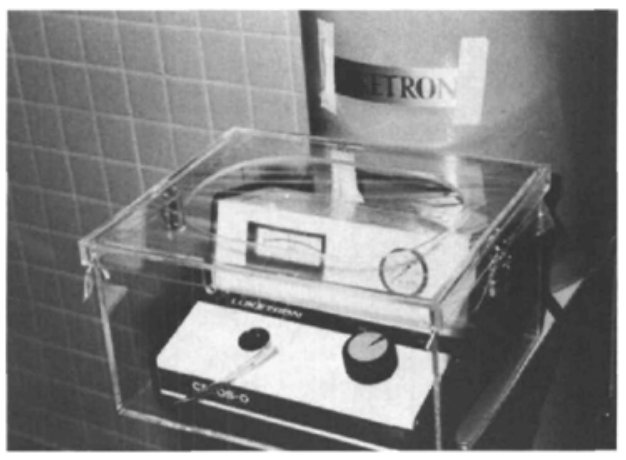

FIGURE Scavenger box with flexible diaphragm.

We have modified the cryoprobe scavenger box, and were able to reduce the $\mathrm{N}_{2} \mathrm{O}$ concentrations to an acceptable level. The concentrations measured just above the scavenger box were about $10 \mathrm{ppm}$. The object of the modification was to avoid pressure buildup within the box, producing leakage of $\mathrm{N}_{2} \mathrm{O}$ from the box. A large oval opening was made to the solid lid as shown on the figure and the opening was covered from inside with a flexible transparent plastic sheet made from a refuse bag. With this simple modification, leakage of nitrous oxide from the scavenger box became negligible.

\author{
Masao Yamashita MD \\ Akitomo Matsuki MD \\ Tsutomu Oyama MD \\ Department of Anaesthesiology \\ Hirosaki University \\ School of Medicine \\ Hirosaki 036 \\ Japan
}

\section{REFERENCES}

1 Gonzalez $E R$. $\mathrm{N}_{2} \mathrm{O}$ exhaust from cryosurgical units may affect physician performance. JAMA 1979; 242: 2379.

2 Wray RP. A source of nonanesthetic nitrous oxide in operating room air. Anesthesiology 1980; 52: 88-9.

3 Marcus DF, Gawecki $S$. Nitrous oxide levels during retinal cryosurgery. Arch Ophthalmol 1981; 99: 457-9.

4 Criteria for a Recommended Standard-Occupational Exposure to Waste Anesthetic Gases and Vapors. National Institute for Occupational Safety and Health, U.S. Department of Health, Education, and Welfare, March 1977, Publication \#77-140.

\section{Respiratory depression following epidural morphine}

To the Editor:

We read with interest the case report of Robinson, Lewis and Elliot (Can Anaesth Soc J 1984; 31 : 5945) which demonstrates the remarkable tolerance of some patients to epidural narcotics. In spite of a massive overdose of narcotic $(50+50 \mathrm{mg}$ of morphine and $25 \mathrm{mg}$ of meperidine within 16 hours), only moderate respiratory depression occurred (maximum $\mathrm{PaCO}_{2}$ 54). We would like to report a recent case which demonstrates the reverse, in that marked respiratory depression occurred after a rather small dose of an epidurally administered narcotic.

A healthy $60 \mathrm{~kg} 49$-year-old man was scheduled for an L4-5 laminectomy and discectomy. Premedi- 
cation consisting of intramuscular morphine $5 \mathrm{mg}$ and promethazine $25 \mathrm{mg}$ was given at 0855 hours. General anaesthesia was induced at 1020 hours, maintained with isoflurane, plus fentanyl which was given in increments to a total of $300 \mu \mathrm{g}$. Following the operation, the orthopaedic surgeon gave at 1230 hours $5 \mathrm{ml}(2.5 \mathrm{mg})$ of a preservativefree morphine solution through a small catheter 4-5 centimeters above the laminotomy site outside the dura. The various layers were closed. This direct application of morphine over the dura to effect postoperative analgesia following spinal operations, has recently been described ' and forms part of a standard protocol by our orthopaedic surgeons.

No analgesics were given in the recovery room. Following discharge to the ward at 1415 hours the patient was monitored for signs of respiratory depression. At 1730 he was found to be somnolent, cyanotic and breathing seven times/minute. Arterial blood gas analysis $\left(\mathrm{Fl}_{\mathrm{O}_{2}}\right.$ 0.21) revealed: $\mathrm{PO}_{2} 29$ $\mathrm{mmHg}, \mathrm{PCO}_{2}$ of $56 \mathrm{mmHg}$. Oxygen was then administered. The respiratory rate fell to four/ minute. Naloxone $0.2 \mathrm{mg}$ was given intravenously over several minutes. The patient became alert and the respiratory rate increased to ten/minute. Repeat arterial blood gas analysis revealed: $\mathrm{PO}_{2} 122$ $\mathrm{mmHg}, \mathrm{PCO}_{2} 51 \mathrm{mmHg}$. Two hours later, the respiratory rate again decreased to six breaths/ minute. Naloxone $0.1 \mathrm{mg}$ was injected intravenously at hourly intervals until the following morning. The postoperative course thereafter was uneventful.

We report this interesting case to highlight the vast range of susceptibility to the respiratory depressant effects of epidurally administered narcotics, in this case given by the surgeon. Although not apparent at the time of operation, an inadvertently created opening in the dura cannot be definitely ruled out, allowing direct entry into the subarachnoid space of a portion of the morphine-containing solution. The morphine concentraion in the CSF might therefore have been significantly higher than usual. This case supports the need for close postoperative observation of such patients in order to avoid a tragedy.

\section{Christopher Jyu MD}

Jonathan D. Lamb MD FRCP(C)

Department of Anaesthesia

University Hospital

Saskatoon, Saskatchewan

\section{REFERENCE}

1 Rechtine GR, Reinert CM, Bohlman NH. The use of epidural morphine to decrease post operative pain in patients undergoing lumbar laminectomy. $\mathrm{J}$ Bone and Joint Surg 1984; 66: 113-6.

\section{Erratum}

Re: Palazzo, M.G.A., Strunin, L. Anaesthesia and emesis. II. Prevention and management. Can Anaesth Soc J 1984; 31: 407-416 (July).

The sentence (page 413, line 27, right hand column) "Our drug of choice for prophylaxis would be droperidol $0.175 \mathrm{mg} \cdot \mathrm{kg}^{-1}$ intravenously, given peroperatively, although a smaller dose can be effective."

should read

"Our drug of choice for prophylaxis would be droperidol $0.0175 \mathrm{mg} \cdot \mathrm{kg}^{-1}$ intravenously, given peroperatively, although a smaller dose can be effective." 